\title{
Special Issue: British Society for Cardiovascular Research
}

\section{Introduction}

\author{
David J. Grieve ${ }^{1}$
}

Published online: 20 March 2019

(C) Springer Science+Business Media, LLC, part of Springer Nature 2019

As Honorary Secretary of the British Society for Cardiovascular Research (BSCR), I am delighted to introduce our first special issue of Cardiovascular Drugs and Therapy focussed on proceedings of the BSCR Autumn meeting which was held at the University of Sheffield in September 2018.

The society was first established in 1973 and now comprises $>450$ members from both basic and clinical science backgrounds with broad interests in cardiac and vascular research [1]. Its aim is to provide a forum to promote understanding of the cardiovascular system from both a biomedical and healthcare perspective towards improved diagnosis, prevention and treatment of cardiovascular disease. It organises two annual research meetings which adopt a themed symposium format comprising state-of-the-art contributions by prominent UK and international researchers, which are held in June together with the British Atherosclerosis Society as the Basic Science Track of the British Cardiovascular Society annual conference, and in September as a stand-alone BSCR focussed meeting.

In 2010, the BSCR was fortunate to receive a major bequest from the late Bernard and Joan Marshall, the uncle and aunt of Professor David Hearse, one of the founding members of the society. This generous gift has allowed the BSCR to host the annual "Bernard and Joan Marshall Research Awards session" at its Autumn meeting, which in 2018 comprised the keynote Distinguished Investigator lecture from Professor Hanjoong Jo (Emory University and Georgia Tech, Atlanta) and presentations by five short-listed finalists competing for the Early Career Investigator Award [2]. The latter provides significant support to one of the central objectives of the society which is to recognise and encourage the work of the next generation of cardiovascular researchers. This special issue of Cardiovascular Drugs and Therapy includes short review articles from each of the Early

David J. Grieve

d.grieve@qub.ac.uk

1 Centre for Experimental Medicine, Queen's University Belfast, Belfast BT9 7AE, UK
Career Investigator finalists [3-7], which are based on their original research published in leading journals, including Arteriosclerosis Thrombosis and Vascular Biology, Circulation, Circulation Research, Nature Protocols and the New England Journal of Medicine, together with the accepted abstracts from the BSCR Autumn 2018 meeting.

This special issue reflects the developing relationship between the BSCR and Cardiovascular Drugs and Therapy which also includes provision for BSCR member submissions to the journal which are linked through the BSCR website. I hope that you enjoy reading the high quality articles in this issue and that this may prompt some of you, who are not already members, to join the BSCR (https://bscr.org/).

\section{References}

1. Davidson SM, Hearse D. Reflections on 40 years of the British Society for Cardiovascular Research (BSCR). Heart. 2013;99:1551-3.

2. Fragiadaki M, Evans PC. The Bernard and Joan Marshall Early Career Investigators and Distinguished Investigator award 2018. Cardiovasc Drugs Ther. 2019, this issue.

3. Chiesa ST, Charakida M. High-density lipoprotein function and dysfunction in health and disease. Cardiovasc Drugs Ther. 2019, this issue .

4. Kaier TE, Alaour B, Marber M. Cardiac myosin-binding protein C from bench to improved diagnosis of acute myocardial infarction. Cardiovasc Drugs Ther. 2019, this issue.

5. Mahmoud M, Souilhol C, Serbanovic-Canic J, Evans P. GATA4Twist1 signalling in disturbed flow-induced atherosclerosis. Cardiovasc Drugs Ther. 2019, this issue.

6. Watson SA, Terracciano CM, Perbellini F. Myocardial slices: an intermediate complexity platform for translational cardiovascular research. Cardiovasc Drugs Ther. 2019, this issue.

7. Saxton SN, Withers SB, Heagerty AM. Emerging roles of sympathetic nerves and inflammation in perivascular adipose tissue. Cardiovasc Drugs Ther. 2019, this issue.

Publisher's Note Springer Nature remains neutral with regard to jurisdictional claims in published maps and institutional affiliations. 